\title{
Estudo morfoanatômico das folhas de Cuphea glutinosa Cham. \& Schltdl., Lythraceae
}

\author{
Adriana Maria Zago, ${ }^{1}$ Melânia Palermo Manfron, ${ }^{1,2}$ Ademir Farias Morel, ${ }^{3}$ \\ Gilberto Dolejal Zanetti ${ }^{*}$,
}

\author{
${ }^{1}$ Programa de Pós-graduação em Ciências Farmacêuticas, Centro de Ciências da saúde, Universidade Federal de \\ Santa Maria, Prédio 26, 97105-900 Santa Maria-RS, Brasil, \\ ${ }^{2}$ Departamento de Farmácia Industrial, Centro de Ciências da Saúde, Universidade Federal de Santa Maria, \\ Prédio 26, 97105-900 Santa Maria-RS, Brasil, \\ ${ }^{3}$ Departamento de Química, Centro de Ciências Naturais e Exatas, Universidade Federal de Santa Maria, Prédio 18, \\ 97105-900 Santa Maria-RS, Brasil.
}

\begin{abstract}
RESUMO: Adeterminação de características macro e microscópicas das folhas de Cuphea glutinosa Cham. \& Schltdl., Lythraceae, foi o objetivo deste trabalho. Esta planta é utilizada tradicionalmente como medicinal. As características macroscópicas das folhas como a forma, a textura e a consistência, bem como o ápice e a base da lâmina foliar são relevantes na determinação da autenticidade de insumos farmacêuticos desta espécie. Microscopicamente a presença de formações epicuticulares, cristais de oxalato de cálcio na forma de drusas, tricomas tectores e glandulares, estômatos do tipo diacítico, células mucilaginosas e floema interxilemático são características úteis no controle botânico de qualidade desta planta como insumo farmacêutico, quando analisados em conjunto.
\end{abstract}

Unitermos: Cuphea glutinosa, farmacobotânica, Lythraceae.

\begin{abstract}
Morpho-anatomical study of the leaves of Cuphea glutinosa Cham. et Schltdl. (Lythraceae). The determination of macroscopic and microscopic characteristics of Cuphea glutinosa Cham. \& Schltdl., Lythraceae, leaves were the aim of this work. This plant is traditionally used as medicinal. The macroscopic characteristics of the leaves as the shape, texture and consistency as well as the apex and the base of the leaf are relevant to determinate pharmaceutical insumes autenticity of this plant. In the leaves microscopy there are epicuticular formations, crystals of calcium oxalate in the form of druses, and glandular trichomes, xerophytytic stoma of the diacytic type, mucilaginous cells, and interxilematic phloem are important characteristics in the botanical quality control of this plant as pharmaceutical insume.
\end{abstract}

Keywords: Cuphea glutinosa, pharmaco botany, Lythraceae.

\section{INTRODUÇ̃̃OO}

A família Lythraceae é composta por aproximadamente trinta gêneros e quinhentas espécies. Esta família apresenta distribuição pantropical e suas espécies são, frequentemente, plantas lenhosas, mas também ocorrem ervas anuais (Barroso, 1991; Schultz, 1985; Reitz, 1969). O gênero Cuphea compreende cerca de 250 espécies centro-sul americanas. Para a diagnose do gênero Cuphea é destacado a presença de duas bractéolas em flores não opostas, folhas decussadas e estames insertos na metade superior da corola (Kissmann \& Groth, 1991; Reitz, 1969).

As partes aéreas de plantas do gênero Cuphea são utilizadas tradicionalmente como estomáquica, anticancerígena, contraceptiva, antifebril, diurética, laxativa, emenagoga e no combate a sífilis, a gonorréia, a arterioesclerose, a hipertensão arterial, a hemorróidas e a arritimias cardíacas (Chen et al., 1999; Daros et al., 1996; Gonzáles et al., 1994). Cuphea glutinosa Cham. et Schltdl., é citada como uma espécie tradicionalmente utilizada como medicinal (Gonzáles et al., 1994). Esta espécie, em geral, forma pequenas aglomerações nos campos do sul do Brasil, Bolívia, Paraguai, Uruguai e centro-leste da Argentina (Reitz, 1969).

Para o gênero Cuphea foi determinado a presença de flavonóides, triterpenóides e ácidos graxos de cadeia curta e média, além de taninos hidrolizáveis, incluindo elagitaninos dímeros com estruturas macrocíclicas (Chen et al., 1999). A maioria dos flavonóides são flavonas e flavonóides 3-O-glicosídeos e, além de derivados de ramnetina e isoramnetina e o padrão geral de flavonóides das sementes embasa uma proposta de segregação deste gênero, bem como na diferenciação entre diversas 
espécies da família Lythraceae (Santos et al., 1995). A atividade antitumoral dos quatro dímeros de taninos hidrolizáveis macrocíclicos, isolados de gênero Cuphea, foi avaliada por Wang e colaboradores (1999) e todos estes quatro compostos químicos inibiram significativamente o crescimento de carcinoma humano de linhagem de células KB, HeLa, DU-145, Hep 3B, S-180 e de células leucêmicas HL-60, mostrando menor citotoxicidade do que a adriamicina contra células da linhagem normal (WISH).

Para espécies do gênero Cuphea o estudo farmacobotânico é de fundamental importância, visto que Cuphea glutinosa, C. carthagenensis e C. ingrata, espécies conhecidas popularmente por sete-sangria, são morfologicamente muito similares entre si (Reitz, 1969; Kissmann \& Groth, 1991) e os parâmetros morfoanatômicos podem ser utilizados como um recurso útil no controle farmacobotânico de qualidade, fato que permite a autenticidade do material vegetal (Souza et al., 2005; Di Stasi, 1996).

Este trabalho tem por objetivo a determinação de características macro-microscópicas de folhas de $C$. glutinosa com a finalidade de contribuir para o controle farmacobotânico de qualidade desta espécie como insumo farmacêutico.

\section{MATERIAL E MÉTODOS}

As folhas de Cuphea glutinosa Cham. \& Schltdl., Lythraceae, foram coletados em Santana do LivramentoRS, Brasil, sendo que uma amostra do material vegetal foi identificado e depositado no Herbário do Departamento de Biologia, do Centro de Ciências Naturais e Exatas da Universidade Federal de Santa Maria, conforme exsicata SMDB 11116.

A análise morfológica foi realizada com a utilização de estereomicroscópio binocular, e a descrição macroscópica foi realizada segundo Gattuso \& Gattuso (1999), Oliveira \& Akisue (1989), Hickey (1974), Stritmatter (1973) e Felipe \& Alencastro (1966).

Para a análise anatômica foram utilizadas seções paradérmicas e transversais. As seções paradérmicas foram realizadas com material fresco e a mão livre, em lâminas semipermanentes, utilizando glicerol como meio de inclusão (Gattuso \& Gattuso, 1999). Para a análise da seção transversal, a parte mediano-apical das folhas foram secionadas $(2 \times 2 \mathrm{~mm})$, fixadas em glutaraldeido a $2 \%$ em tampão fosfato de sóio, $\mathrm{pH}$ 7,2 e conservados, sob refrigeração a $4{ }^{\circ} \mathrm{C}$, por $48 \mathrm{~h}$. O material foi desidratado em série etílica ascendente de 50 a $96^{\circ}$ e incluídos em blocos de hidroxietilmetacrilato, conforme Ruetze \& Schimitt (1986), Gerrits \& Smit (1983). No micrótono rotativo fezse seções de $4 \mu \mathrm{m}$, que foram levadas a banho histológico, repassadas para lâmina e coradas com azul de toluidina $0,05 \%$ (Gerlach, 1977). Após a coloração a lamínula foi fixada sobre as seções com bálsamo sintético entellan. A presença de mucilagens foi detectada pela utilização de tinta da china a $0,25 \%$ e azul de metileno a $0,15 \%$ (Costa, 1982). A constituição química dos cristais foi verificada com ácido acético a $6 \%$ ou ácido clorídrico a $7 \%$. As seções foram analisadas de acordo com Dickson (2000), Appezatto-da-Glória \& Carmello-Guerreiro (2003), Fahn (1990) e Oliveira \& Akisue (1991). O material foi microfotografado em microscópio com câmara digital e as lâminas depositadas no laminário do Departamento de Farmácia Industrial, Universidade Federal de Santa Maria.

\section{RESULTADOS}

\section{Análise macroscópica}

As folhas de Cuphea glutinosa Cham. \& Schltdl., Lythraceae (Figura 1A e B) apresentam filotaxia opostacruzada. O limbo é simples, atinge em média, 9 × 2,5 mm de tamanho, possui forma oblonga a lanceolada, ápice agudo, base simétrica e margem ciliada. Apresenta-se levemente discolor, possui textura áspera e viscosa, consistência subcartácea e esparsos tricomas brancacentos. A venação é do tipo peninérvea e a nervura central é proeminente na face abaxial. O pecíolo é reto e curto, atingindo em média comprimento inferior a $1 \mathrm{~mm}$. Em seção transversal o pecíolo é obtuso-quadrangular.

\section{Análise microscópica da folha}

Em seção paradérmica (Figura 2A e B) as células epidérmicas são sinuosas na face adaxial e ondeadas na face abaxial. Os estômatos são do tipo diacítico nas duas faces epidérmicas. Ocorrem tricomas tectores em forma de ampola, com cutícula verrucosa e ápice afilado nas duas faces epidérmicas.

Em seção transversal, a epiderme é unisseriada. As células epidérmicas sempre apresentam a parede periclinal de tamanho semelhante ou maior que a anticlinal (Figuras 4 e 5). Na face abaxial da lâmina foliar, as células epidérmicas alcançam um menor tamanho em relação às que estão na face adaxial e, na região da nervura central, estas células assumem forma ovóide (Figuras 3 e 4). Células de mucilagem ocorrem frequentemente por toda a extensão epidérmica da Lâmina foliar (Figuras 4 e 5). Estas células de mucilagem são maiores do que as outras células epidérmicas. A cutícula é espessa, plicada e, na face adaxial junto à região da nervura central, exibe formações lenticulares (Figuras 3 a 5). Os estômatos, pequenos e com cristas evidentes, são do tipo mesocítico (Figuras 3, 4 e 6). Por toda a epiderme ocorrem tricomas tectores e glandulares. Os tricomas tectores podem ser uni ou pluricelulares (Figuras 4 e 5). Os tricomas glandulares ocorrem com mais frequência na região distal. Estes tricomas glandulares são pluricelulares e possuem a parte glandular na base da estrutura (Figura 6). 


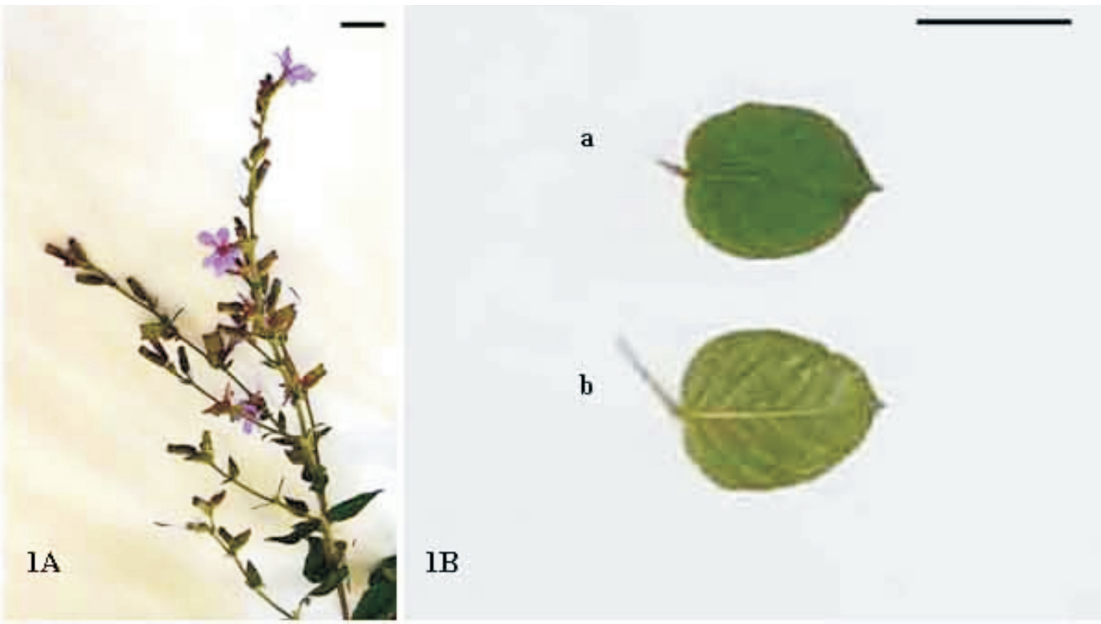

Figura 1A. Aspecto geral dos ramos floridos de Cuphea glutinosa Cham. et Schltdl. 1B. Detalhe da folha de Cuphea glutinosa Cham. et Schltdl. Escala: $1 \mathrm{~cm}$. Legenda: a. face adaxial; b. Face abaxial.
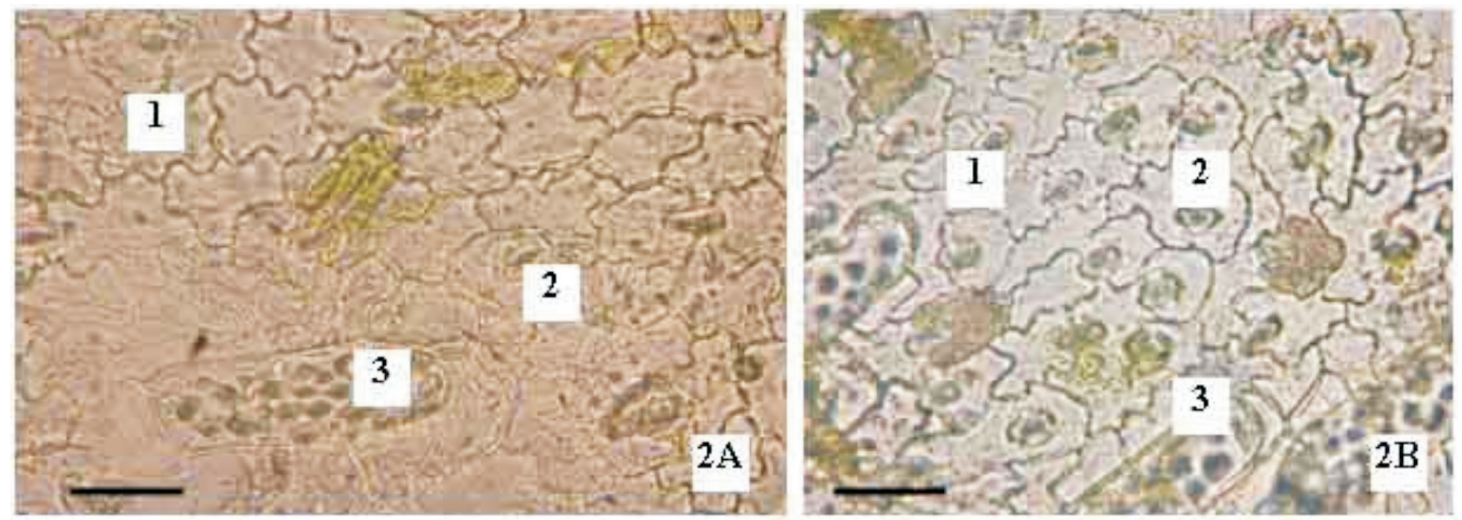

Figura 2. Seção paradérmica da lâmina foliar de Cuphea glutinosa Cham. et Schltdl. 2A. Epiderme na face adaxial. 2B. Epiderme na face abaxial. Escala $20 \mu \mathrm{m}$. Legenda: 1. células epidérmicas; 2. estômato; 3. tricoma tector.

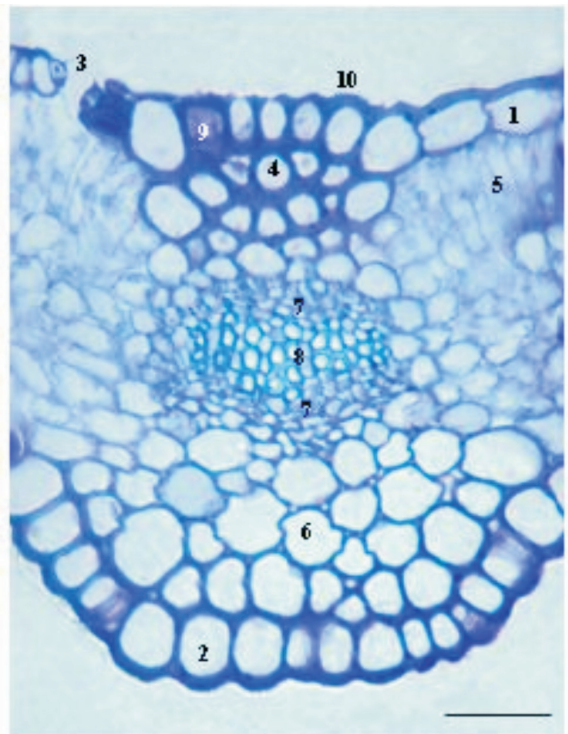

Figura 3. Seção transversal da região central da lâmina foliar de Cuphea glutinosa Cham. et Schltdl. Escala: $20 \mu \mathrm{m}$. Legenda: 1. epiderme na face adaxial; 2 . epiderme na face abaxial; 3 . estômato; 4. colênquima; 5. parênquima paliçádico; 6. parênquima esponjoso; 7. floema; 8. xilema; 9. célula mucilaginosa; 10. cutícula com formações epicuticulares.

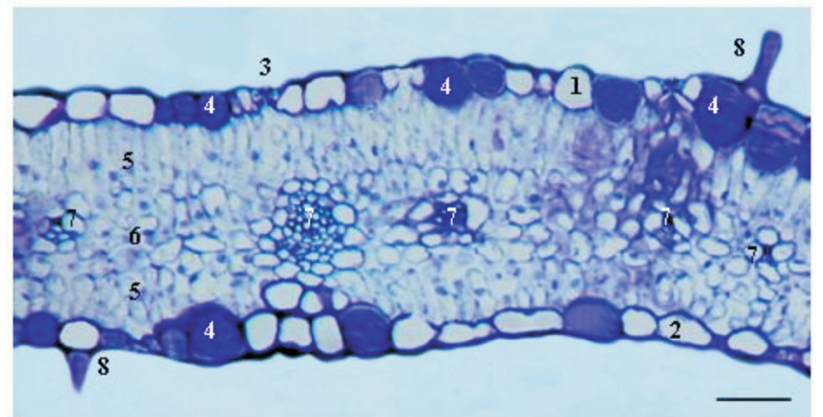

Figura 4. Seção transversal da região lateral da lâmina foliar de Cuphea glutinosa Cham. et Schltdl.. Escala: $20 \mu \mathrm{m}$. Legenda: 1. epiderme na face adaxial; 2 . epiderme na face abaxial; 3 . estômato; 4. célula mucilaginosa; 5 . parênquima paliçádico; 6 . parênquima esponjoso; 7. feixe vascular protegido por bainha parenquimática; 8 . tricoma tector. 

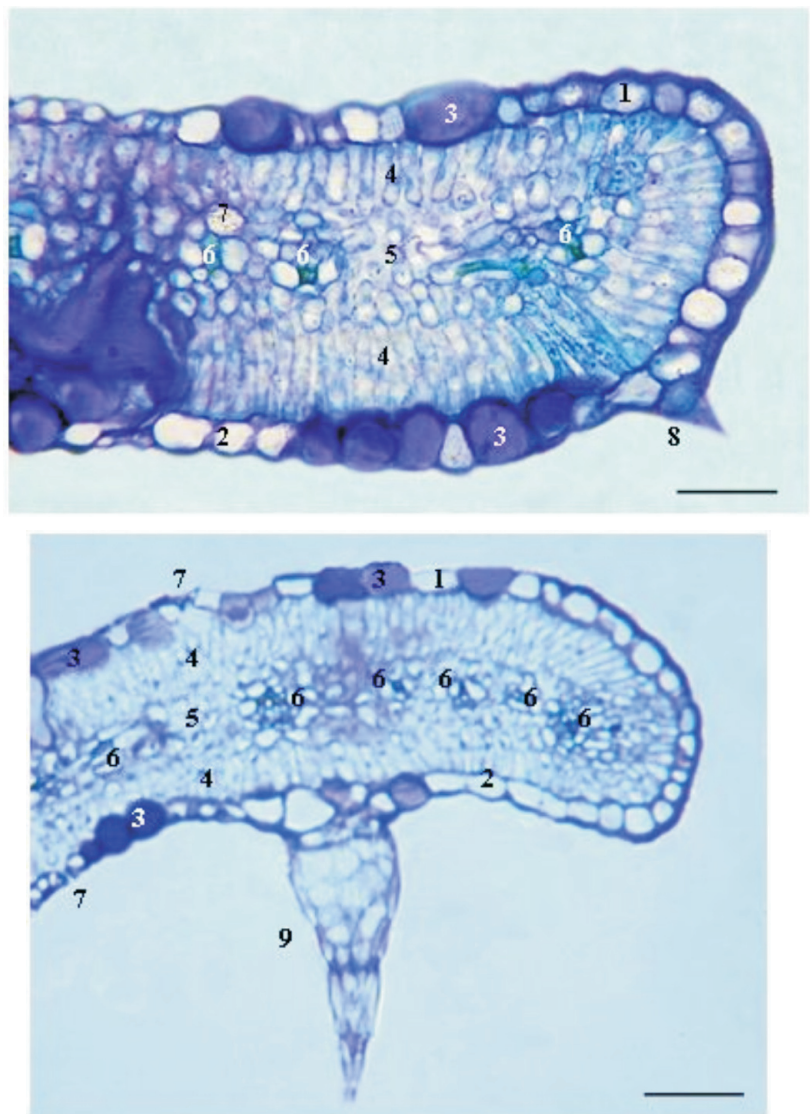

Figura 5 e 6. Seção transversal da região distal da lâmina foliar de Cuphea glutinosa Cham. et Schltdl. Escala: $20 \mu \mathrm{m}$. Legenda: 1. epiderme na face adaxial; 2 . epiderme na face abaxial; 3 . célula mucilaginosa; 4. parênquima paliçádico; 5. parênquima esponjoso; 6. feixe vascular protegido por bainha parenquimática; 7. drusa; 8. tricoma tector; 9. tricoma glandular.

O mesofilo é heterogêneo do tipo isofacial, com o parênquima paliçádico (superior e inferior) constituído por apenas uma camada de células. As células da paliçada superior são maiores em comprimento do que as da paliçada inferior (Figuras 4 a 6). O parênquima esponjoso possui dois a quatro estratos de células com forma ovóide e espaço intercelular do tipo câmara. Neste parênquima, na região próxima aos feixes vasculares menores, é evidente a ocorrência de idioblastos com cristais na forma de drusas (Figuras 4 a 6).

A região da nervura central, em seção transversal (Figura 3), é levemente reentrante na face adaxial e exibe contorno convexo na face abaxial. Subjacente à epiderme, ocorre um colênquima anular constituído, geralmente, por três camadas na face adaxial e até duas camadas na face abaxial. Além desta formação colenquimática ocorrem poucas camadas de parênquima esponjoso com células de forma circular e espaços intercelulares do tipo meato. $\mathrm{O}$ feixe vascular é constituido de xilema rodeado por floema, caracterizando o tipo bicolateral.

As nervuras laterais também são constituídas por feixes vasculares do tipo bicolateral. Estes feixes vasculares encontram-se protegidos por uma bainha vascular parenquimática, que pode ser melhor observada nos feixes de menor ordem (Figuras 4 a 6).

\section{DISCUSSÃO}

$\mathrm{Na}$ análise macroscópica das folhas de Cuphea glutinosa Cham. \& Schltdl., Lythraceae, foi verificado que os caracteres morfológicos coincidem com os descritos para a família Lythraceae (Joly, 1998; Oliveira \& Akisue, 1989; Cronquist, 1991). Características como filotaxia oposta-cruzada, folhas com limbo simples, forma oblonga a lanceolada, venação do tipo peninérvea ápice agudo, base simétrica e margem ciliada foram observadas neste trabalho para a espécie em questão e são concordantes com a literatura (Kissmann \& Groth, 1991; Reitz, 1969). As características como a forma, a textura, a consistência, a base e o ápice da lâmina foliar são relevantes na diferenciação das diferentes espécies no gênero Cuphea. Assim é que espécies como $C$. racemosa apresenta lâmina foliar ovada, enquanto que $C$. fruticos possui lâmina foliar elíptica ou linear (Kissmann \& Groth, 1991).

A presença de floema interxilemático, presença de cristais próximos aos feixes vasculares e células mucilaginosas na epiderme, constatadas em C. glutinosa, são características anatômicas comuns para a família Lythraceae (Metcalfe \& Chalk, 1988). As variações e particularidades que ocorrem nestas características que são comuns para a referida família constituem-se como marcadores anatômicos importantes na determinação de gêneros ou de espécies desta família botânica. Por outro lado, características como o tipo de estômato e de mesofilo, encontrado em C. glutinosa é marcante para esta espécie, pois o tipo comum de estômato e de mesofilo para a família Lythraceae é, respectivamente, o anomocítico e o dorsiventral e não o diacítico e o isofacial tipos morfológicos que foram constatados para a espécie em estudo (Metcalfe \& Chalk, 1950).

As características da cutícula e das formações epicuticulares são marcadores anatômicos relevantes na diferença entre espécies vegetais (Dickson, 2000; Fahn, 1990). Em C. glutinosa a cutícula, presente nas folhas, é plicada em toda a sua extensão. Esta característica a diferencia de plantas medicinais como Syzygium cumini, em que a cutícula se mostra tanto plicada como reta nas diferentes regiões da epiderme foliar (Alberton et al., 2001). Em C. glutinosa, na região junto à nervura central, fica evidente a ocorrência de formações lenticulares. Esta característica cutícular também é relevante na autenticidade desta espécie, pois a ornamentação cuticular revela-se como um importante caráter taxonômico (Dickson, 2000; Cutter, 1987).

As células epidérmicas de C. glutinosa, em vista frontal, são sinuosas (face adaxial) e ondeadas (face abaxial), características que se constituem como um caráter adaptativo contra a perda excessiva de água (Medri \& Lieras, 1980). A ocorrência natural de C. glutinosa em 
formações de campos abertos, ambiente com luminosidade intensa e temperatura que atinge grandes oscilações, explicaria tais características epidérmicas (Reitz, 1969; Porto, 2002).

Uma característica microscópica marcante em C. glutinosa constitui-se na presença de tricomas por toda a epiderme foliar. A presença destas estruturas pode ser útil no controle de qualidade de drogas vegetais, principalmente quando a droga se apresenta fragmentada ou mesmo pulverizada (Oliveira et al., 1993). A frequência e o tamanho dos tricomas podem variar em razão das condições ambientais, de forma que a classificação do tipo de tricomas é mais consistente para a autenticidade de drogas vegetais (Metcalfe \& Chalk, 1988). O tipo morfológico de ampola e a rugosidade que a cutícula assume nos tricomas tectores, bem como os mesmos serem uni ou pluricelulares, os tornam estruturas epidérmicas características para esta espécie vegetal. Em geral os tricomas são discutidos como anexos epidérmicos capazes de reduzirem a transpiração ao produzirem uma camada de ar parado que retém vapor, além do que, as folhas pubescentes tendem a ser mais efetivas na reflexão da radiação solar (Hallahan et al., 2000; Ricklefs, 1993; Fahn, 1986). Estas considerações vêm ao encontro da ocupação natural de $C$. glutinosa em locais de campo aberto, ambiente que exige certa proteção em relação à transpiração excessiva e também na reflexão da radiação luminosa intensa. Por outro lado, estas estruturas epidérmicas também estão associadas ao papel de defesa das plantas à ação de herbívoros e fitopatógenos, pois tanto a quantidade quanto o tipo anatômico podem dificultar o sucesso de processos como os de pouso e oviposição (Holmes \& Keiller, 2002; Gurevitch et al., 2002; Gruenhegen \& Perring, 2001). Em relação aos tricomas glandulares que ocorrem em C. glutinosa os mesmos apresentam estruturas semelhantes aos descritos por Metcalfe \& Chalk (1950) para o gênero Cuphea.

Em C. glutinosa, foi observado apenas cristais de oxalato de cálcio e somente na forma de drusas, próximo aos feixes vasculares de segunda e terceira ordem. Verificouse que os cristais são de oxalato de cálcio, utilizando-se ácido acético a $6 \%$, onde os mesmos são insolúveis, ou ácido clorídrico a 7\%, onde estes cristais solubilizam-se sem produzirem efervescência.

Os cristais, nas suas mais variadas formas, localização e constituição química, revelam-se como uma característica importante na autenticidade de drogas vegetais (Alberton et al., 2001). Nas células do mesofilo foliar de Phyllanthus niruri, pode ser observado cristais de oxalato de cálcio, na forma de drusas, caráter que a distingue de Phyllanthus tenellus (Garcia et al., 2004). Além da presença ou ausência de cristais, a forma e a localização topográfica destas estruturas constituem-se como características importantes em farmacobotânica. È destacado para o gênero Dieffenbachia, a presença de drusas e a ausência de ráfides na epiderme foliar de Dieffenbachia picta, características que a diferem de Dieffenbachia maculata, pois esta última apresenta drusas no mesofilo e ráfides no mesofilo e na epiderme foliar (Genua \& Hillson, 1985). É destacado como funções relacionadas a estes cristais a defesa à herbivoria, a concentração e difusão luminosa, a regulação metabólica de cálcio, bem como a detoxificação de ácido oxálico ou de metais pesados e a sustentação dos mais variados tecidos vegetais (Nataka, 2003). Por outro lado é sugerida uma relação funcional entre as células mucilaginosas e os cristais de oxalato de cálcio (Trachtenberg \& Mayer, 1981). Os cristais teriam função no suprimento de cálcio, que seria transferido para as células mucilaginosas, ligando-se às pectinas e auxiliando, em última análise, no armazenamento de água, desta forma tem-se novamente mais uma justificativa que poderia explicar à ocupação natural de C. glutinosa em ambientes de campo aberto, mesmo porque é muito frequente a presença de células mucilaginosas nesta espécie vegetal.

A ocorrência de células mucilaginosas na lâmina foliar é uma característica marcante a ser destacada para $C$. glutinosa. Azul de toluidina foi o reagente utilizado neste trabalho para detectar tais células de mucilagem, pois cora de púrpura as substâncias pécticas que constituem as mucilagens (O’Brien \& Mc Cully, 1981). A presença destas células mucilaginosas foi confirmada pela utilização de tinta da china ou azul de metileno em seções de material fresco de C. glutinosa. Os ensaios histoquímicos com estes dois reagentes são práticos e tiram proveito da propriedade que as mucilagens têm em reterem água, tornando mais clara as células em que estes metabólitos encontram-se armazenados (Costa, 1982).

Dentre os diferentes grupos taxonômicos a localização histológica de compostos mucilaginosos é constante (Sajo \& Rudall, 2002; Baker \& Gerritsen, 1992; Costa, 1982). Esta característica das mucilagens tornase fundamental na identificação de inúmeras espécies vegetais, pois é agregado valor taxonômico à presença destas células mucilaginosas e, consequentemente, na autenticidade de um determinado material botânico. Estas células mucilaginosas constituem-se em uma característica xeromórfica, atuando basicamente na manutenção de água para as folhas e outros órgãos vegetais (Sajo \& Rudall, 2002; Metcalfe \& Chalk, 1950). Também é mencionado de que as células mucilaginosas podem desempenhar o papel de filtrar a luz, protegendo o parênquima paliçádico nas folhas (Metcalfe \& Chalk, 1950).

\section{CONCLUSÕES}

As características macroscópicas das folhas de $C$. glutinosa como a forma, a textura e a consistência, bem como o ápice e a base da lâmina foliar são relevantes na determinação da autenticidade de insumos farmacêuticos desta espécie. Microscopicamente, a presença de formações epicuticulares lenticulares, drusas, estômatos diacíticos, tricomas tectores e glandulares, células 
mucilaginosas e floema interxilemático são caracteres que, quando analisados em conjunto, auxiliam no controle botânico de qualidade da planta em questão como insumo farmacêutico.

\section{REFERÊNCIAS}

Alberton JR, Ribeiro A, Sacramento LVS, Franco SL, Lima MAP 2001. Caracterização farmacognóstica do jambolão (Syzypiam cumini (L.) Skeels). Rev Bras Farmacogn 11: 37-50.

Appezzato-da-Glória B, Carmello-Guerreiro SM 2003. Anatomia Vegetal. Viçosa: UFV.

Baker ME, Gerritsen AF 1992. The development of mucilage cells in Hibiscus schizopetalus. Blumea 36: 411-438.

Barroso GM 1991. Sistemática de angiospermas do Brasil. vol. 2.Viçossa: UFV.

Chen GL, Yen, YK, Yang LL, Hatono T, Okuda T, Yoshida, T 1999. Macrocyclic ellagitannin dimers, cuphiins D1 and D2, and accompanying tannins from Cuphea hyssopifolia. Phytochemistry 50: 307-312.

Costa AF 1982. Farmacognosia. vol. III. Lisboa: Fundação Calouste Gulbenkian.

Cronquist A 1981. Na integrated system of classification of flowering plants. New York: Columbia University Press.

Cutter EG 1987. Anatomia vegetal. Órgãos. Experimentos e interpretações. São Paulo: Rocca.

Daros MR, Farias MR, Caro MSB, Simões, CMO 1996. Caracterização de um derivado da quercetina em Cuphea carthagenensis (Jacq.) Mcbride. XIV Simpósio de Plantas Medicinais do Brasil, Florianópolis, Brasil.

Dickson WC 2000. Integrative plant anatomy. San Diego: Academic Press.

Di Stasi LC 1996. Plantas medicinais: Arte e ciência. São Paulo: UNESP.

Fahn A 1986. Structural and functional properties of trichomes of xeromorphic leaves. Ann Bot 57: 631-637.

Fahn A 1990. Plant anatomy. Oxford: Pergamon Press.

Felipe GM, Alencastro FMMR 1966. Contribuição ao estudo da nervação foliar das compostas de cerrado. I - Tribos Helinieae, Heliantheae, Inuleae, Mutisieae e Senecioneae. An Acad Bras Cienc 38: 125-157.

Garcia CM, Zanetti GD, Zago AM, Bittencourt CF, Heinzmann BM 2004. Estudo morfo-anatômico de Phyllanthus niruri L. e Phyllanthus tenellus Roxb. Acta Farm Bonaer 23: 67-70.

Gattuso MA, Gattuso SJ 1999. Manual de procedimentos para analisis de drogas em polvo. Rosário: Universidade Nacional de Rosário, Argentina.

Genua JM, Hillson CJ 1985. The occurrence, type and location of calcium oxalate crystals in the leaves of fourteen species of Araceae. Ann Bot 56: 351-361.

Gerlach D 1977. Bothanische mikrotechnik. 2 ed. Stuttgard: Georg-Thieme Verlag.

Gerrits PO, Smith L 1983. A new, less toxic polimerization system for the embedding of soft tissue in glycol methacrylate and subsequent preparing of serial section. $J$ Microsc 132: 81-85.

González AG, Valencia E, Bermejo Barrera J, Grupta MP 1994. Chemical components of Cuphea species. Carthagenol: a new triterpene from C. carthagenensis. Planta Med 60: 592-593.

Gruenhegen NM, Perring TM 2001. Impact of leaf trichomes on parasitoid behavior and parasitism of silverleaf whiteflies (Homptera: Aleyrodidae). Southwest Entomol 26: 279290.

Gurevitch J, Scheiner SM, Fox GA 2002. The ecology of plants. Sinauer Associates, Inc. Sunderland: Massachusetts.

Hallahan DL, Gray JC, Callow JA 2000. Advances in botanical research: incorporating Advances in Plant Pathology Plant Trichomes. San Diego: Academic Press.

Hickey LJ 1974. Classification de la arquitetura de las hojas de dicotiledoneas. Bol Soc Arg Bot 16: 1-26.

Holmes MG, Keiller DR 2002. Effects of pubescence and waxes on the reflectance of leaves in the ultraviolet and photosynthetic wavebands: a comparison of a range of species. Plant Cell Environ 25: 85-93.

Joly AB 1998. Botânica: Introdução à taxonomia vegetal. 12 ed. São Paulo: ed. Nacional.

Kissmann KG, Groth D 1991. Plantas infestantes e nocivas. vol. III. São Paulo: BASF.

Medri ME, Lieras E 1980. Aspectos da anatomia ecológica das folhas de Hevea brasiliensis Muell. Acta Amaz 10: 463493.

Metcalfe CR, Chalk L 1950. Anatomy of the dicotyledons. vol. 1. Oxford: Claredon press.

Metcalfe CR, Chalk L 1988. Anatomy of the dicotyledons. vol. 1, 2 ed., Oxford: Claredon Press.

Nakata PA 2003. Advances in our understanding of calcium oxalate crystal formation and function in plants. Plant Sci 164: 901-909.

O' Brien TP, Mc Cully ME 1981. The study of plant structure principles and selected methods. Melbourne: Termocarphipty.

Oliveira F, Akisue G 1989. Fundamentos de farmacobotânica. São Paulo: Atheneu.

Oliveira F, Akisue G 1991. Farmacobotânica. São Paulo: Atheneu.

Oliveira F, Lúcia M, Garcia LO 1993. Caracterização farmacognóstica da droga e do extrato fluido de mentrasto-Ageratum conyzoides L. Lecta 11: 63-100.

Porto ML 2002. Os campos sulinos: sustentabilidade e manejo. Cien Nat 24: 119-138.

Reitz R 1969. Flora Ilustrada Catarinense. Lythraceae. Itajaí: Herbário Barbosa Rodrigues.

Ricklefs RE 1993. A economia da natureza. Rio de Janeiro: Guanabara Koogan.

Ruetze M, Schimitt U 1986. Glycol-methacrylat (GMA) als einberttungssystem fúr histologische untersuchungen von koniferen-Nadeln. Eur J Forest Pathol 16: 321-324.

Sajo MG, Rudall PJ 2002. Leaf and stem anatomy of Vochysiaceae in relation to subfamilial systematics. Bot J Linn Soc 138: 
339-364.

Santos DYAC, Salatino MLF, Salatino A 1995. Flavonoids of species of Cuphea (Lythraceae) from Brazil. Biochem Syst Ecol 23: 99-103.

Schultz A 1985. Introdução à botânica sistemática. vol. 2, 5 ed., Porto Alegre: UFRGS.

Souza TJT, Manfron MP, Zanetti, GD, Holezel SCSM, Pagliarin VP 2005. Análise morfo-histológica e fitoquímica de Vebena litoralis Kunt. Acta Farm Bonaer 24: 209-214.

Stritmatter CGD 1973. Nueva tecnica de diafanización. Bol Soc Arg Bot 15: 126-129.

Trachtenberg S, Mayer AM 1981. Calcium oxalate crystal in Opuntia ficus-indica: development and relation to mucilage cells A stereologicalanalysis. Protoplasma 109: 271-283.

Wang CC, Chen LG, Yang LL 1999. Antitumor activity of four macrocyclic ellagitannins from Cuphea hyssopifolia. Cancer Lett 140: 195-200. 